\title{
Apicidin, a novel histone deacetylase inhibitor, has profound anti-growth activity in human endometrial and ovarian cancer cells
}

\author{
TAMI UEDA, NORIYUKI TAKAI, MASAKAZU NISHIDA, KAEI NASU and HISASHI NARAHARA \\ Department of Obstetrics and Gynecology, Oita University Faculty of Medicine, Oita, Japan
}

Received August 21, 2006; Acepted October 18, 2006

\begin{abstract}
Histone deacetylase inhibitors (HDACIs) can inhibit proliferation, induce cell cycle arrest and stimulate apoptosis of cancer cells. Our purpose was to investigate the antiproliferative effects of a novel HDACI, apicidin, on the Ishikawa endometrial cancer cell line, the SK-OV-3 ovarian cancer cell line and normal human endometrial epithelial cells. Endometrial and ovarian cancer cells were treated with various concentrations of apicidin, and the effects on cell growth, cell cycle, apoptosis and related measurements were investigated. MTT assays showed that all endometrial and ovarian cancer cell lines were sensitive to the growth inhibitory effect of apicidin, although normal endometrial epithelial cells were viable after the treatment with the same doses of apicidin that induced the growth inhibition of endometrial and ovarian cancer cells. Cell cycle analysis indicated that their exposure to apicidin decreased the proportion of cells in S-phase and increased the proportion in G0/G1 and/or G2/M phases of the cell cycle. Induction of apoptosis was confirmed by Annexin V staining of externalized phosphatidylserine and loss of the transmembrane potential of mitochondria. This induction occurred in concert with the altered expression of $\mathrm{p} 21^{\mathrm{WAF} 1}, \mathrm{p} 27^{\mathrm{KIP} 1}, \mathrm{p} 16$, cyclin $\mathrm{A}$, and E-cadherin. Furthermore, apicidin treatment of these cell lines increased acetylation of $\mathrm{H} 3$ and $\mathrm{H} 4$ histone tails. These results suggest that apicidin exhibits the antiproliferative effects through selective induction of genes related to cell growth, malignant phenotype, and apoptosis. The findings raise the possibility that apicidin may prove particularly effective in the treatment of endometrial and ovarian cancers.
\end{abstract}

Correspondence to: Dr Noriyuki Takai, Department of Obstetrics and Gynecology, Oita University Faculty of Medicine, 1-1 Idaigaoka, Hasama-machi, Yufu-shi, Oita 879-5593, Japan

E-mail: takai@med.oita-u.ac.jp

Key words: apicidin, apoptosis, cell cycle, endometrial cancer, ovarian cancer

\section{Introduction}

Endometrial and ovarian cancers are the most common malignant tumors of the female genital tract. The incidence of endometrial cancer has increased in recent years, accounting for $\sim 13 \%$ of female cancers (1). Early stages of ovarian cancer are frequently asymptomatic and difficult to detect, and thus diagnosis usually occurs after the disease has advanced. The search for agents effective in the treatment of either advanced or recurrent gynecological cancer has been disappointing. To date, cisplatin, doxorubicin, and paclitaxel demonstrate the greatest efficacy $(2,3)$. However, although reported response rates have been as high as $70 \%$, the duration of the responses remains brief, from 4 to 8 months. Therefore, innovative approaches are needed for the treatment of gynecological cancer.

Local remodeling of chromatin and dynamic changes in the nucleosomal packing of DNA are key steps in the regulation of gene expression, consequently affecting proper cell function, differentiation and proliferation. Chromatin structure may affect transcriptional activation by blocking the assembly of the basal transcriptional machinery to form the preinitiation complex $(4,5)$. One of the most important mechanisms in chromatin remodeling is the post-translational modification of the $\mathrm{N}$-terminal tails of histones by acetylation, which contributes to a 'histone code' determining the activity of target genes (6). Transcriptionally silent chromatin is composed of nucleosomes in which the histones have low levels of acetylation on the lysine residues of their aminoterminal tails. Acetylation of histone proteins neutralizes the positive charge on lysine residues and disrupts nucleosome structure, allowing the unfolding of the associated DNA, subsequent access by transcription factors, and changes in gene expression.

Apicidin is a novel cyclic tetrapeptide with a potent broad spectrum of antiprotozoal activity against Apicomplexan parasites (7). The chemical structure of apicidin is depicted in Fig. 1. Its structure is related to trapoxin, a potent HDACI, and some biological activity including antiproliferative and toxic effects has been shown in some cancer cell lines (8). However, the biological activity of apicidin in endometrial and ovarian cancer cells has not been clarified. In this study, we examined whether apicidin was able to mediate inhibition of cell growth, cell cycle arrest, apoptosis, and the expression of genes related to the malignant phenotype in the 
endometrial cell line Ishikawa and the ovarian cancer cell line SK-OV-3. Furthermore, we compared the sensitivity of apicidin to normal endometrial epithelial cells with that to endometrial cancer cells.

\section{Materials and methods}

Materials. Apicidin [cyclo $\left(\mathrm{N}-\mathrm{O}\right.$-methyl- ${ }_{\mathrm{L}}$-tryptophanyl- ${ }_{\mathrm{L}^{-}}$ isoleucinyl ${ }_{\mathrm{D}}$-pipecolinyl- ${ }_{\mathrm{L}}$-2-amino-8-oxodecanoyl)] was purchased from Calbiochem (Darmstadt, Germany) and resuspended in dimethyl sulphoxide (DMSO).

Cell lines. The Ishikawa human cell line was kindly provided by Dr Masato Nishida (Tsukuba University, Ibaraki, Japan), and the SK-OV-3 human cell line was obtained from the American Type Culture Collection (ATCC, Manassas, VA, USA).

Cell culture. The human endometrial cancer cell line Ishikawa was grown in DMEM, and the human ovarian cancer cell line SK-OV-3 was maintained in RPMI-1640, each supplemented with $10 \%$ heat-inactivated fetal bovine serum (FBS), penicillin $(10,000 \mathrm{U} / \mathrm{ml})$, and streptomycin $(10 \mathrm{mg} / \mathrm{ml})$ (all from Gibco, Rockville, MD).

Normal endometrial specimens were obtained from ten pre-menopausal patients who had undergone hysterectomies for leiomyoma. All patients had been free of any hormonal treatments before the operation. All of the specimens were diagnosed as being from the late proliferative phase (11-13th day of the menstrual cycle) using a standard histological examination of endometrial tissues. This study was approved by the Institutional Review Board (IRB) of the Faculty of Medicine, Oita University, and written informed consent was obtained from all patients. Normal endometrial epithelial cells were separated from stromal cells by digesting the tissue fragments with collagenase. Briefly, the tissue was minced into 2- to 3-mm pieces and incubated with collagenase (200 U/ml) (Gibco) in RPMI-1640 medium (Gibco) with stirring for $40 \mathrm{~min}$ at $37^{\circ} \mathrm{C}$. The suspension was then filtered through a $150-\mu \mathrm{m}$ wire sieve to remove mucus and undigested tissue. The filtrate was then passed through an $80-\mu \mathrm{m}$ wire sieve, which allowed the stromal cells to pass through while the intact glands were retained. After washing three times with serum-free RPMI-1640, normal human endometrial epithelial cells were transferred to culture flasks (Corning, $\mathrm{NY}$ ) at a density of $10^{6}$ cells $/ \mathrm{ml}$ in RPMI-1640 supplemented with $10 \%$ heat-inactivated fetal bovine serum (FBS), streptomycin $(100 \mathrm{U} / \mathrm{ml})$, and penicillin $(100 \mathrm{U} / \mathrm{ml})$. After $16 \mathrm{~h}$, the attached cells, which were $>98 \%$ pure as analysed by immunocytochemical staining with antibodies to keratin, vimentin (V9), factor VIII, and leukocyte common antigen (2B11+PD7/26) (all from Dako, Copenhagen, Denmark), were used for the experiments. The cultures were incubated at $37^{\circ} \mathrm{C}$ in an atmosphere of $5 \% \mathrm{CO}_{2}$ in air at $100 \%$ humidity.

Growth studies. Cells were seeded at an initial density of $10^{4}$ per well in 96-well plates, incubated for $24 \mathrm{~h}$, and treated with various concentrations $\left(1 \times 10^{-7}-1 \times 10^{-5}\right)$ of apicidin. After 3 days, cell viability was determined by 3-(4,5-dimethylthiazol-2-yl)-2,5-diphenyltetrazolium bromide (MTT) assay

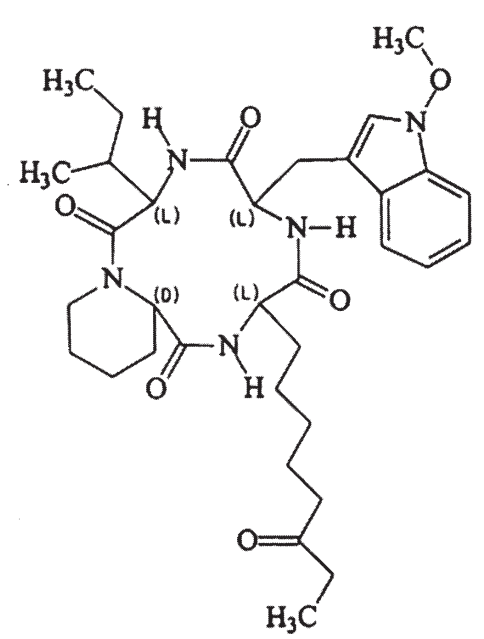

Figure 1. The chemical structure of apicidin.

kit (CHEMICON International, Inc., CA). The cells were stained with $200 \mu \mathrm{g} / \mathrm{ml}$ MTT and lysed in 5\% SDS, and the absorbance was read at $540 \mathrm{~nm}$ using a 96-well plate reader. All experiments were performed independently at least three times in triplicate per experimental point.

Cell cycle analysis by flow cytometry. The cells were cultured for $48 \mathrm{~h}$ with and without apicidin, trypsinized, washed in PBS and fixed with $70 \%$ ethanol/PBS. They were then treated with $0.25 \mu \mathrm{g} / \mathrm{ml}$ RNase (MP Biomedicals, Inc., $\mathrm{OH}, \mathrm{USA}$ ), and incubated at $37^{\circ} \mathrm{C}$ for $30 \mathrm{~min}$. Nuclei were stained with $50 \mu \mathrm{g} / \mathrm{ml}$ propidium iodide, and the relative DNA content was analyzed using a FACScalibur flow cytometer equipped with CellQuest software (BectonDickinson Immunocytometry Systems, San Jose, CA).

Annexin $V$ staining. The Annexin $\mathrm{V}$ assays were performed according to the manufacturer's protocol (BioVision, Mountain View, CA). Briefly, the cultured cells were collected, washed with binding buffer, and incubated in $500 \mu 1$ of a binding buffer containing $5 \mu \mathrm{l}$ of Annexin-V-FITC. The nuclei were counterstained with propidium iodide. The percentage of apoptotic cells was determined using the FACScalibur flow cytometer.

Assessment of the mitochondrial transmembrane potential. The mitochondrial transmembrane potential was assayed using the MitoCapture ${ }^{\mathrm{TM}}$ mitochondrial apoptosis detection kit (BioVision). Briefly, cells were collected, washed twice with PBS and incubated with $1 \mathrm{ml}$ of the diluted MitoCapture solution at $37^{\circ} \mathrm{C}$ for $20 \mathrm{~min}$. MitoCapture intensity was determined using the FACScalibur flow cytometer.

Western blot analysis. Expression of specific proteins was detected by Western blotting. Cells were washed twice in PBS, suspended in lysis buffer (50 mM Tris, $\mathrm{pH} 8.0,125 \mathrm{mM}$ $\mathrm{NaCl}, 0.1 \%$ Nonidet P- $40,5 \mathrm{mM}$ ethylenediamine tetraacetic acid, $50 \mathrm{mM} \mathrm{NaF}$, and $0.1 \%$ phenylmethylsulfonyl fluoride), and placed on ice for $30 \mathrm{~min}$. After centrifugation at 15,000 rpm for $15 \mathrm{~min}$ at $4^{\circ} \mathrm{C}$, the supernatant was collected. Protein 

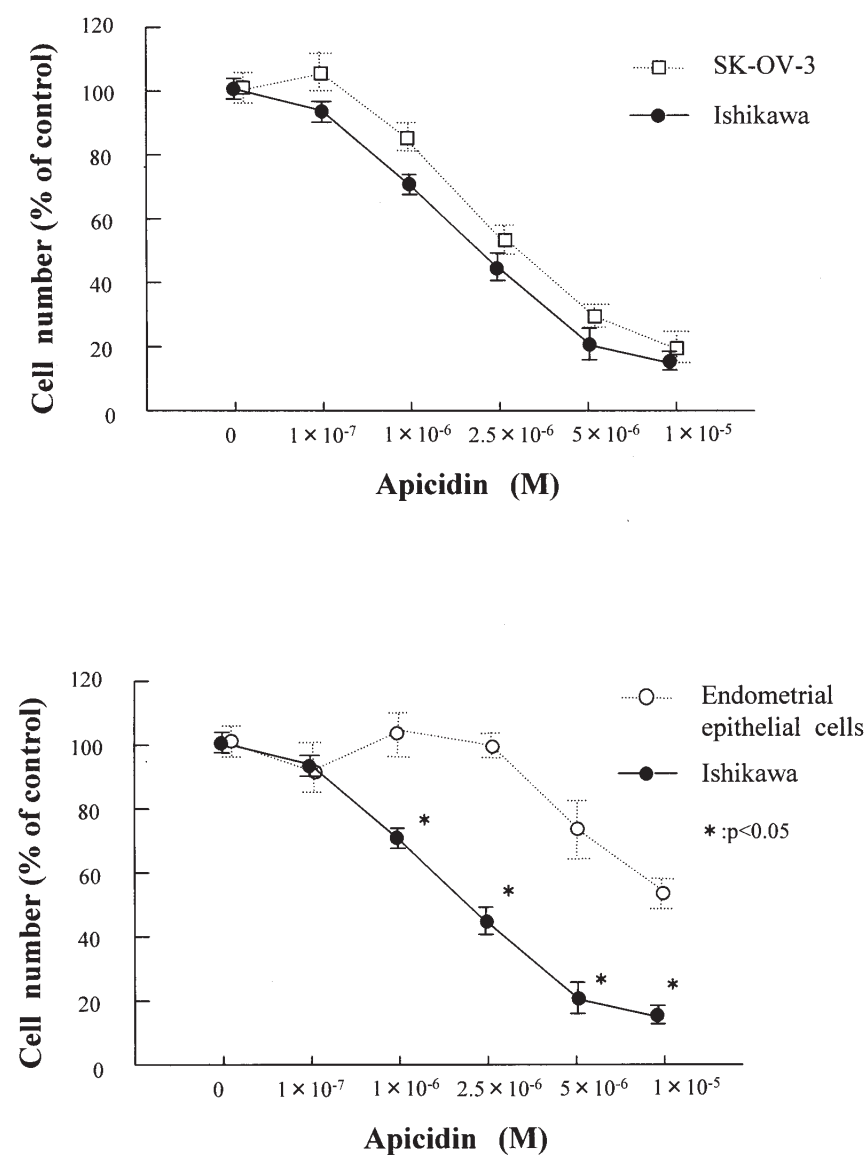

Figure 2. Dose-response effects of apicidin on the survival of human endometrial cancer and ovarian cancer cell lines and normal endometrial epithelial cells in culture. Cells were treated with apicidin $\left(1 \times 10^{-7}-1 \times 10^{-5}\right)$ for $72 \mathrm{~h}$ in 96-well plates. The cells were then stained with MTT and lysed, and the absorbency was read in a plate reader using a 540-nm filter. Surviving cells were calculated as percentage control. Results represent the mean \pm SD of three independent experiments with triplicate wells $(\mathrm{p}<0.05)$.

concentrations were quantitated using the Coomassie protein assay reagent (Pierce, Rockford, IL). Whole cell protein extract was resolved with sodium dodecyl sulfate-polyacrylamide gel electrophoresis using a $10 \%$ polyacrylamide gel under reduced conditions. After transfer to Immobilon polyvinylidene transfer membranes (Millpore, Bedford, MA), the protein was stained with Ponceau S (Sigma-Aldrich) to verify uniform loading and transfer. Membranes were blocked with 5\% skim milk (Becton-Dickinson) in Trisbuffered saline with Tween-20 (50 mM Tris- $\mathrm{HCl}, 150 \mathrm{mM}$ $\mathrm{NaCl}$, and $0.1 \%$ Tween-20, $\mathrm{pH}$ 7.4) (TBS-T) overnight and subsequently incubated with primary antibodies [cyclin A, p16, p27 KIP1, E-cadherin (BD Biosciences, San Diego, CA), p2 $1^{\mathrm{WAF} 1}$ (Oncogene Research Products, San Diego, CA), glyceraldehyde-3-phosphate-dehydrogenase (GAPDH) (Ambion, Austin, TX), and acetyl-histone-H3, acetyl-histoneH4 (Upstate, Lake Placid, NY)] with the appropriate dilutions overnight. The membranes were washed three times with TBS-T and incubated with the appropriate horseradish peroxidase-conjugated secondary antibody for $1 \mathrm{~h}$ at room temperature. Subsequently, the membranes were washed three times with TBS-T and analyzed by enhanced chemiluminescence (Amersham Pharmacia Biotech, Chicago, IL).
Statistical analysis. Data are presented as the means \pm SD and were appropriately analyzed by the Mann-Whitney U-test and Bonferroni/Dunn test with StatView 4.5 (Abacus Concepts, Berkeley, CA, USA). p $<0.05$ was accepted as statistically significant.

\section{Results}

Effect of apicidin on the proliferation of endometrial and ovarian cancer cells and normal endometrial epithelial cells. As shown in Fig. 2, the growth of Ishikawa and SK-OV-3 cells was inhibited by apicidin in a dose-dependent manner. The effective dose of the apicidin that inhibited $50 \%$ clonal growth $\left(\mathrm{ED}_{50}\right)$ of the endometrial and ovarian cancer cell lines ranged between $1.0 \times 10^{-6}$ and $2.5 \times 10^{-6} \mathrm{M}$.

The growth of the endometrial cancer cells tested was more sensitive to apicidin than the normal endometrial epithelial cells (Fig. 2). The normal endometrial epithelial cells showed only $70 \%$ of control-growth inhibition at $5.0 \times 10^{-6} \mathrm{M}$ apicidin, whereas Ishikawa endometrial cancer cells showed $20 \%$ of control-growth inhibition at the same dose.

Cell cycle analysis of endometrial and ovarian cancer cells after exposure to apicidin. The effects of apicidin on the cell cycle of the endometrial and ovarian cancer cells were determined. Ishikawa cells cultured for $48 \mathrm{~h}$ in the presence of apicidin showed an accumulation of endometrial cancer cells in both G0/G1 and G2/M phases of the cell cycle at a low concentration of apicidin $\left(5 \times 10^{-7} \mathrm{M}\right)$, and $\mathrm{G} 2 / \mathrm{M}$ phase at a high concentration $\left(1 \times 10^{-6} \mathrm{M}\right)$ with a concomitant decrease in the proportion of those in S phase (Fig. 3). A total of 58.8\% of the untreated Ishikawa cells were in $\mathrm{G} 0 / \mathrm{G} 1$ compared with $65.2 \%$ of cells cultured with apicidin $5 \times 10^{-7} \mathrm{M}$, and $13.6 \%$ of the Ishikawa untreated cells were in $\mathrm{G} 2 / \mathrm{M}$ compared with $21.2 \%$ of cells cultured with apicidin $5 \times 10^{-7} \mathrm{M}$, and $33.7 \%$ with $1 \times 10^{-6} \mathrm{M}$.

SK-OV-3 cells showed an accumulation in the G0/G1 phase at both concentrations $\left(5 \times 10^{-7}\right.$ and $\left.1 \times 10^{-6} \mathrm{M}\right)$ with a decrease in the proportion of those in $\mathrm{S}$ phase. A total $57.6 \%$ of the untreated SK-OV-3 cells were in G0/G1 compared with $63.2 \%$ of cells cultured with apicidin $1 \times 10^{-6} \mathrm{M}$, and $67.4 \%$ with $2.5 \times 10^{-6} \mathrm{M}$ (data not shown).

Effect of apicidin on the induction of apoptosis. The strong antiproliferative effect of apicidin on Ishikawa and SK-OV-3 cells observed in vitro may be caused in part by the induction of apoptosis. To test this, we used two different methods.

The proportion of apoptotic cells was determined by the Annexin V/FITC kit. As shown in Fig. 4, after $48 \mathrm{~h}$ of treatment with $1 \times 10^{-6} \mathrm{M}$ apicidin, $35.5 \%$ of Ishikawa cells and $22.6 \%$ of SK-OV-3 cells displayed high Annexin V/FITC and low PI staining, indicating apoptosis. Secondary necrotic cells, which had high Annexin V/FITC and PI staining, included $38.3 \%$ of Ishikawa cells and $15.8 \%$ of SK-OV-3 cells.

After treatment with apicidin $1 \times 10^{-6} \mathrm{M}$ for $48 \mathrm{~h}$, the number of Ishikawa cells displaying low MitoCapture staining increased to $64.6 \%$, and SK-OV-3 cells to $55.0 \%$, indicating loss of the mitochondrial transmembrane potential that occurs following induction of apoptosis (Fig. 5). 
A

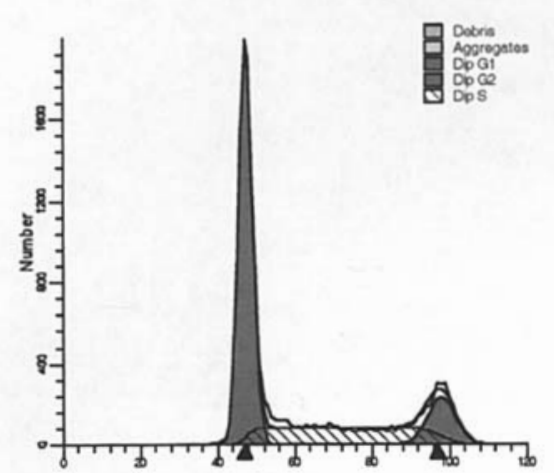

$\mathrm{C}$

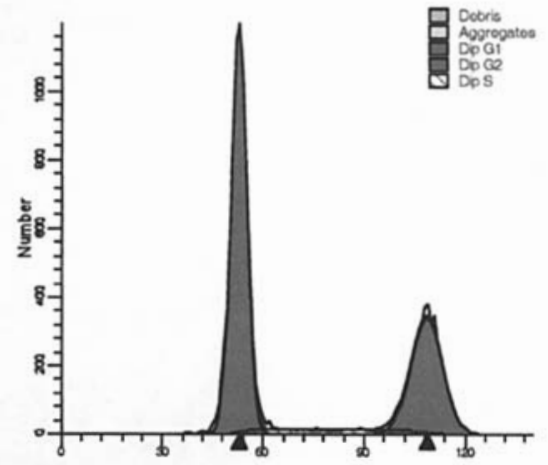

B

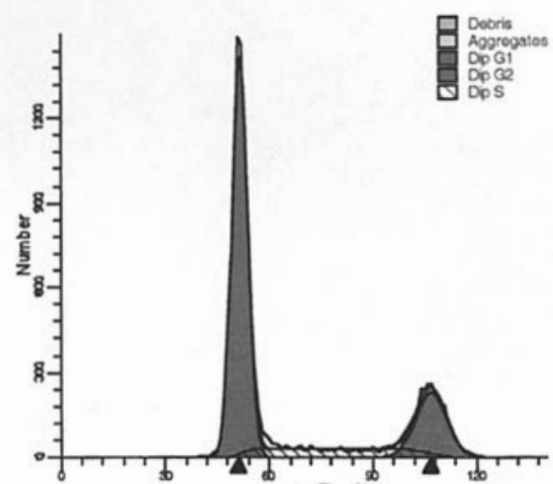

A: untreated

$\mathrm{G} 0 / \mathrm{G} 1 ; 58.8 \%$

$\mathrm{S} ; \quad 27.6 \%$

G2/M ; $13.6 \%$

B: Apicidin $5 \times 10^{-7} \mathrm{M}$

G0/G1; 65.2\%

$\mathrm{S} ; \quad 13.6 \%$

$\mathrm{G} 2 / \mathrm{M} ; 21.2 \%$

\section{C: Apicidin $1 \times 10^{-6} \mathrm{M}$ \\ $\mathrm{G} 0 / \mathrm{G} 1 ; 58.6 \%$ \\ $\mathrm{S} ; \quad 7.7 \%$ \\ G2/M ; 33.7\%}

Figure 3. Cell cycle analysis of Ishikawa cells by flow cytometry. Ishikawa cells were cultured with apicidin $\left(5 \times 10^{-7}-1 \times 10^{-6}\right)$ for 48 h, harvested and stained with propidium iodide (PI). Control cells were treated with vehicle alone. Cell cycle analysis was performed by flow cytometry (see Materials and methods). The results of a representative study are shown; two additional experiments yielded similar results.
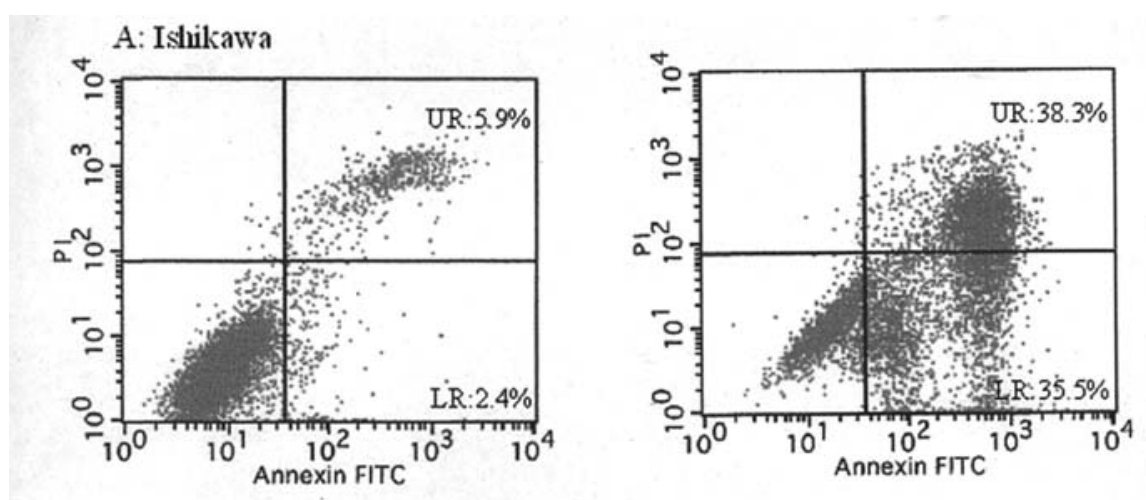

B: SK-OV-3
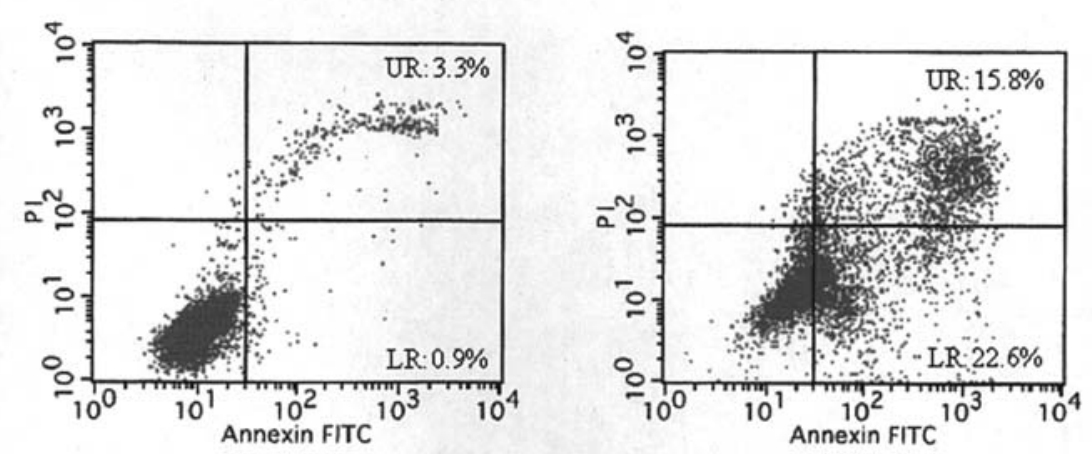

Figure 4. Induction of apoptosis by apicidin in Ishikawa and SKOV-3 cells detected by Annexin V-FITC and PI staining. Cells were cultured with $1 \times 10^{-6}$ M apicidin for $48 \mathrm{~h}$, stained with Annexin V-FITC and PI, and analysed by flow cytometry. Lower right quadrants, percentage of early apoptotic cells; and upper right quadrants, secondary necrotic cells. Three duplicate experiments were performed with similar results. 

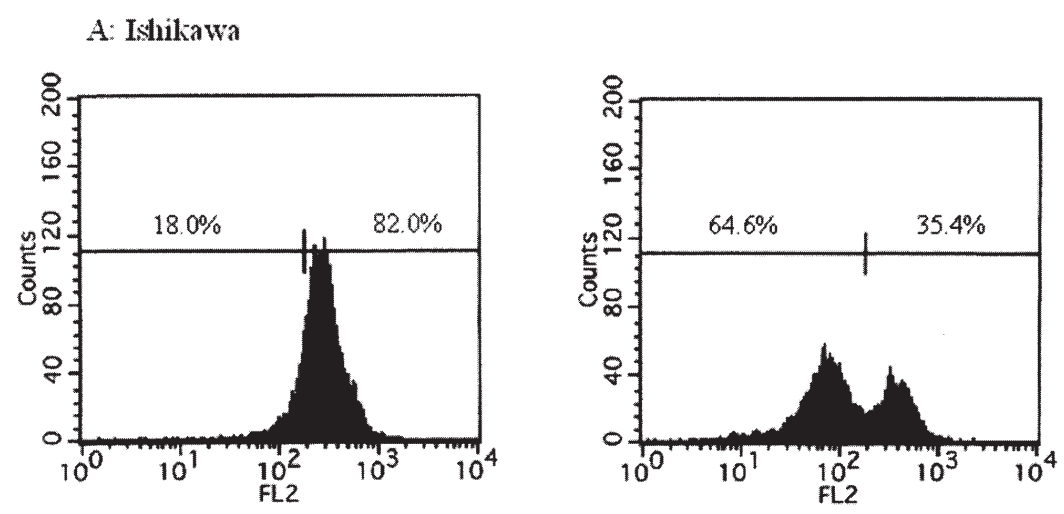

B: SK $-\mathrm{OV}-3$
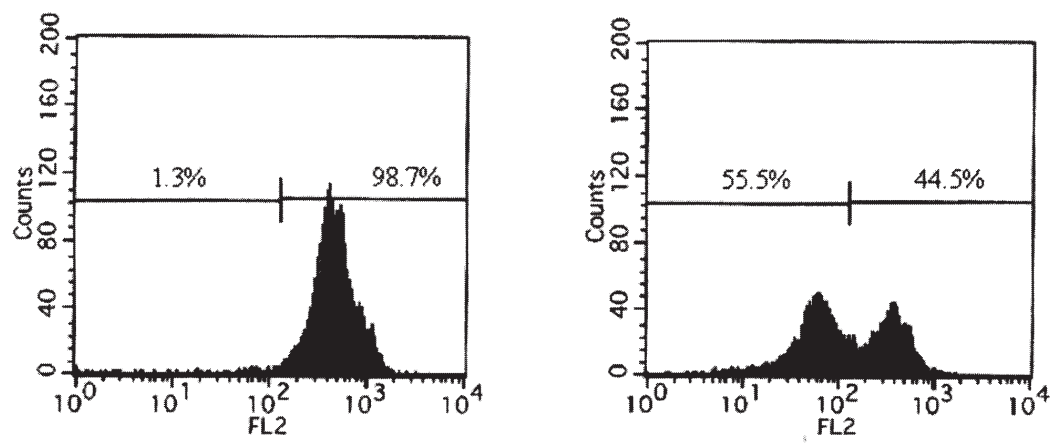

Figure 5. Effect of apicidin treatment on the mitochondrial transmembrane potential. Cells were cultured with $1 \times 10^{-6} \mathrm{M}$ apicidin for $48 \mathrm{~h}$, and the MitoCapture intensity was determined by flow cytometry. FL2 indicates MitoCapture intensity, representing mitochondrial transmembrane potential. Data represent three duplicate experiments with similar results.

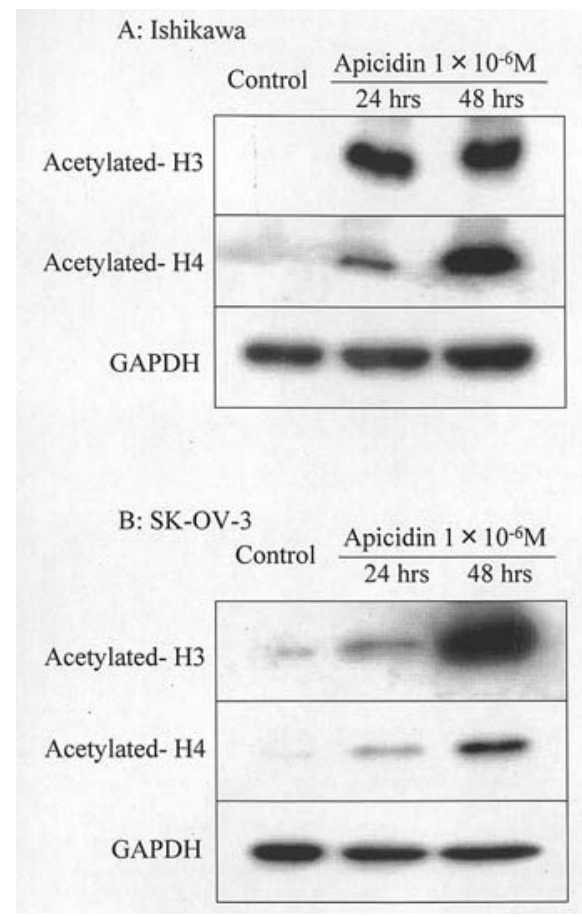

Figure 6. Protein expression of acetylated histone $\mathrm{H} 3$ and $\mathrm{H} 4$ as measured by Western blot analysis. Ishikawa and SKOV-3 cells were treated with $1 \times 10^{-6} \mathrm{M}$ apicidin and cell lysates were harvested after 24 and $48 \mathrm{~h}$. Western blot analysis was performed with a series of antibodies (acetylated histones H3 and H4). Control cells were treated with vehicle alone. The amount of protein was normalized by comparison to levels of GAPDH.
Effect of apicidin on acetylation of histones. The level of histone acetylation in vivo is mainly maintained by the balance between histone acetylase and HDAC. Various HDACIs induce acetylation of histones. To examine the relationship between cell death and histone acetylation of Ishikawa and SK-OV-3 cells, we next analyzed the effect of apicidin on the intracellular level of histone H3 and H4. Treatment of cells with apicidin for 24 and $48 \mathrm{~h}$ dramatically induced the levels of acetylated $\mathrm{H} 3$ and $\mathrm{H} 4$ in a time-dependent manner (Fig. 6).

Effect of apicidin on the expression of cell cycle-and apoptosis-related proteins. $\mathrm{p} 21^{\mathrm{WAF} 1}, \mathrm{p} 27^{\mathrm{KIP} 1}$ and $\mathrm{p} 16$ are cyclin-dependent kinase inhibitors (CDKIs) that bind to cyclindependent kinase complexes and decrease kinase activity, and may act as key regulators of G0/G1 accumulation. We examined the effect of apicidin on the expression of p21 ${ }^{\mathrm{WAF}}$, p27 ${ }^{\mathrm{KIP} 1}$ and p16 by Western blot analysis (Fig. 7). Apicidin markedly up-regulated the level of p21 $1^{\mathrm{WAF} 1}$ and $\mathrm{p} 27^{\mathrm{KIP} 1}$ protein, which was expressed at negligible levels in the untreated endometrial and ovarian cancer cell lines. Expression of p16 protein was observed in untreated cancer cells and was slightly up-regulated by apicidin. Conversely, apicidin decreased the level of cyclin A. Cyclin B and cyclin D3 levels were unchanged (data not shown).

E-cadherin binds to B-catenin and can act as a tumor suppressor gene; its promoter has $\mathrm{CpG}$ islands which are frequently methylated in selected cancers. Apicidin increased 
A

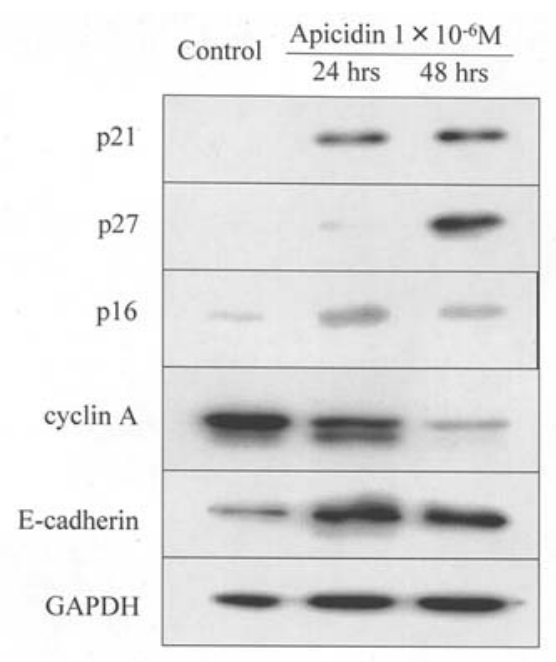

B

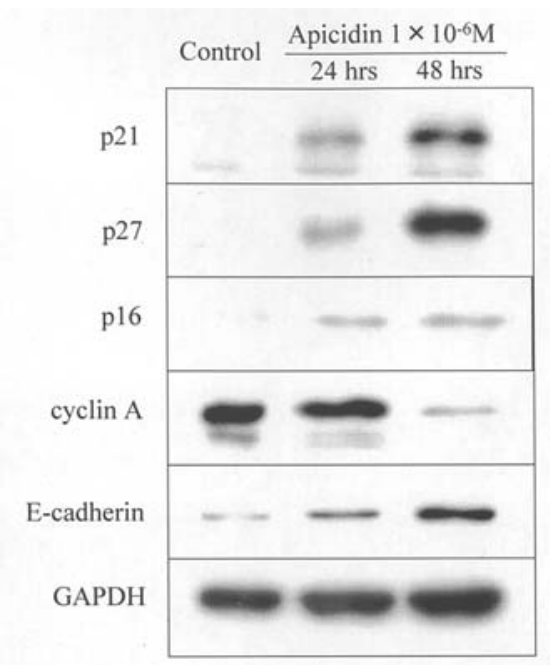

Figure 7. Cell cycle- and apoptosis-related protein expression in Ishikawa cells and SK-OV-3 cells, as measured by Western blot analysis. Ishikawa cells (A) and SK-OV-3 (B) cells were treated with $1 \times 10^{-5} \mathrm{M}$ apicidin, and cell lysates were harvested after 24 and $48 \mathrm{~h}$. Western blot analysis was performed with a series of antibodies: p2 $1^{\mathrm{WAF} 1}, \mathrm{p} 27^{\mathrm{KIP} 1}, \mathrm{p} 16$, cyclin A, and E-cadherin. Control cells were treated with vehicle alone. The amount of protein was normalized by comparison to levels of GAPDH.

the expression level of E-cadherin in Ishikawa and SK-OV-3 cells.

\section{Discussion}

Histone acetylation is regulated by a balance between histone acetyltransferase (HATs) and histone deacetylase (HDAC). To date, four families of HAT (P/CAF, p300/CBP, TAF250, and SRC-1) have been identified $(9,10)$. Although all HATs are able to modify histones in free solution, non-histone targets such as the general transcription factor $\mathrm{Rb}$, transcription factor p53, and erythroid Kuppel-like factor, are also substrates for HATs $(11,12)$, suggesting that HATs may regulate transcription by modifying a variety of promoterbound proteins. Biochemical and molecular biological studies have established that HDACs are components of large multiprotein complexes that target promoter sites through their interaction with sequence-specific transcription (13-16).

Various HDAC inhibitors (HDACIs) such as trichostatin A (17), sodium butyrate (18), trapoxin (8), depudecin, FR901228, oxamflatin, and MS-27-275 inhibit cancer cell growth in vitro and in vivo. They accumulate acetylated histone in the nucleus, and have been demonstrated to arrest cell growth and reverse neoplastic characteristics in cultured cells. Recent evidence suggests that the induction of histone hyperacetylation by HDACIs is responsible for antitumor effects through selective induction of genes, which play an important role in the cell cycle, cell morphology and apoptosis.

Apicidin, a fungal metabolite, has been shown to exhibit antiparasitic activity against apicomplexan parasites by inhibiting their HDACs (18). Additional studies further demonstrated that apicidin exhibits an anti-proliferative effect in various cancer cell lines, such as cervical cancer, breast cancer, leukemia and prostate cancer $(8,19,20)$. Studies by Takai et al indicated that a wide array of HDACIs (SAHA, VPA, TSA and NaB) had a significant growthsuppressing effect on six endometrial (21) and nine ovarian cancer cell lines (22). This stimulated us to examine the effect of apicidin, a novel fungal metabolite on endometrial and ovarian cancer cell lines.

We have demonstrated that apicidin is highly effective in suppressing the growth of human endometrial cancer cell line Ishikawa, and ovarian cancer cell line SKOV-3. The prominent arrest of Ishikawa and SKOV-3 in the G0/G1 phase of the cell cycle is likely to account for this effect. Because acetylation and deacetylation of histone have been shown to play an important role in the regulation of gene expression in eukaryotic cells (23-28), cell cycle arrest at the G1 phase by apicidin might be attributed to alteration of the expression of the genes important to G1-S progression. The expression of $\mathrm{p} 21^{\mathrm{WAF} 1}$ and $\mathrm{p} 27^{\mathrm{KIP} 1}$, which are cyclin-dependent kinase inhibitors, has an important role in blocking the cell cycle in the G1 phase (29). Protein levels of both $\mathrm{p} 21^{\mathrm{WAF} 1}$ and $\mathrm{p} 27^{\mathrm{KIP} 1}$ were found to be increased following treatment of endometrial and ovarian cancer cells with apicidin, supporting their contribution as a possible mechanism by which apicidin inhibits endometrial and ovarian cancer growth. Similar results were obtained with other HDACIs $(21,22)$.

In addition, p16 controls cell cycle proliferation during G1 by inhibiting the ability of cyclin D/CDK4 and cyclin D/CDK6 complexes to phosphorylate retinoblastoma protein (pRb). It can be inactivated via multiple mechanisms including homozygous deletion, point mutation and promoter hypermethylation in various human tumors (30-33). Wong et al (34) reported that methylation of the p16 promoter was detected in $20 \%$ of endometrial cancers, and this alternation is associated with advanced stages and poor prognosis. Apicidin slightly up-regulated the expression of p16.

The E-cadherin gene is involved in cell-cell adhesion, and the loss of E-cadherin protein function has been associated with enhanced metastatic growth of tumor cells (35). Inactivation of this gene by hypermethylation has been observed in breast carcinoma cells (36) and in primary breast tumors (37). Further, hypermethylation of this gene is associated with tumor differentiation and myometrial invasion 
in endometrial cancer (38). We found that transcription of E-cadherin was markedly up-regulated in Ishikawa and SKOV-3 cells treated with apicidin, suggesting a gain of tumor suppressor function in response to the inhibition of HDAC.

Both hypermethylation and histone deacetylation result in transcriptional silencing. Evidence suggests that these processes are often not independent of each other and result in layers of epigenetic silencing. Theoretically, the reversal of both processes should lead to a greater gene transcription than the reversal of one epigenetic layer alone. Using a microarraybased technique that evaluates gene expression in combination with epigenetic change, histone deacetylase inhibitor alone failed to reactivate the expression of genes that $\mathrm{CpG}$ island hypermethylated (39). Although both the p16 and E-cadherin genes are transcriptionally silenced by hypermethylation, apicidin up-regulated both genes in different degrees. In this study, the methylation statuses of these genes were not analyzed, so further analysis may be needed to provide information about this regulation mechanism by apicidin.

Cyclins are defined to be key proteins in the control of cell proliferation. Cyclin A acts from the late G1 phase through the $\mathrm{M}$ phase of the cell cycle, and forms a complex with cdk2 in the late G1-S phase and with cdc2 in the G2/M phase (40). Cyclin A expression is involved in the progression to malignancy of the endometrium and is correlated with proliferative activity and prognostic features (41). Apicidin decreased the expression of cyclin A, and thus modulated the activity of the downstream $\mathrm{pRb} / \mathrm{E} 2 \mathrm{~F}$ axis, thereby triggering cell cycle arrest, especially in the G2/M phase at a higher concentration.

MTT assay showed that the growth of Ishikawa was more sensitive to apicidin than the normal endometrial epithelial cells. Total inhibition of HDAC was speculated to be toxic for human use, despite the non-potent effect of this kind of drug when using low concentration or higher sensitivity of cancer cells compared with normal healthy cells. It has not been clearly identified which gene is targeted by HDACIs, however, they seems to alter the expression of a very limited number of genes, contrary to HDACs in chromatin. Concerning the apoptosis and sensitivity of cancer cells, apicidin may control the expression of genes that regulate oncogenesis. This result suggests that the anticancer activity of apicidin may occur with minimal side-effects, raising hopes that apicidin may become a useful adjuvant therapy for gynecological cancers.

In summary, apicidin exhibits antiproliferative activity and potently induces apoptosis in human endometrial and ovarian cancer cells. These events are accompanied by the induction of $\mathrm{p} 21^{\mathrm{WAF} 1}$ and $\mathrm{p} 27^{\mathrm{KIP} 1}$ and the down-regulation of several antiapoptotic- and cell cycle-related proteins, such as cyclin A. Furthermore, apicidin significantly inhibited the cell growth of endometrial cancers cell compared with that of normal endometrial epithelial cells. These findings suggest that apicidin may be particularly effective in the treatment of endometrial and ovarian cancer. Although many HDACIs are currently under clinical trial, there are several questions which remained to be addressed, since the understanding of HDAC-class enzyme specificity and the knowledge of drug and tumor specificity are still limited. Optimal correlation assays and optimal gene targets remain to be defined.

\section{Acknowledgements}

The study was supported by a Grant-in-Aid (no. 18591840 to Noriyuki Takai) for Scientific Research from the Ministry of Education, Culture, Sports, Science, and Technology, Japan.

\section{References}

1. Covens A, Brunetto VL, Markman M, Orr JW Jr, Lentz SS and Benda J: Phase II trial of danazol in advanced, recurrent, or persistent endometrial cancer: a Gynecologic Oncology Group study. Gynecol Oncol 89: 470-474, 2003.

2. Ball HG, Blessing JA, Lentz SS and Mutch DG: A phase II trial of paclitaxel in patients with advanced or recurrent adenocarcinoma of the endometrium: a Gynecologic Oncology Group study. Gynecol Oncol 62: 278-291, 1996.

3. Thigpen T, Brady MF, Alvarez D, et al: Oral medroxyprogesterone acetate in the treatment of advanced or recurrent endometrial carcinoma: a dose-response study by the Gynecologic Oncology Group (GOG) study. J Clin Oncol 17: 1736-1744, 1999.

4. Felsenfeld G: Chromatin as an essential part of the transcriptional mechanism. Nature 355: 219-224, 1992.

5. Wolffe AP: Transcription: in tune with the histones. Cell 77: 13-16, 1994

6. Strahl BD and Allis CD: The language of covalent histone modifications. Nature 403: 41-45, 2000.

7. Darkin-Rattray SJ, Gurnett AM, Myers RW, et al: Apicidin: a novel antiprotozoal agent that inhibits parasite histone deacetylase. Proc Natl Acad Sci USA 93: 13143-13147, 1996.

8. Han JW, Ahn SH, Park SH, et al: Apicidin, a histone deacetylase inhibitor, inhibits proliferation of tumor cells via

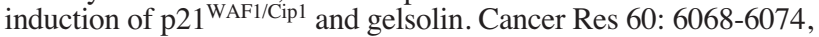
2000.

9. Kijima M, Yoshida M, Sugita K, Horinouchi S and Beppu T: Trapoxin, an antitumor cyclic tetrapeptide, is an irreversible inhibitor of mammalian histone deacetylase. J Biol Chem 268: 22429-22435, 1993

10. Koyama Y, Adachi M, Sekiya M, Takekawa M and Imai K: Histone deacetylase inhibitors suppress IL-2-mediated gene expression prior to induction of apoptosis. Blood 96: 1490-1495, 2000.

11. Gu W and Roeder RG: Activation of p53 sequence-specific DNA binding by acetylation of the p53 C-terminal domain. Cell 90: 595-606, 1997.

12. Zhang W and Bieker JJ: Acetylation and modulation of erythroid Kuppel-like factor (EKLF) activity by interaction with histone acetyltransferases. Proc Natl Acad Sci USA 95: 9855-9860, 1998.

13. Pazin MJ and Kadonaga JT: What's up and down with histone deacetylation and transcription? Cell 89: 325-328, 1997.

14. Wolffe AP: Transcriptional control. Sinful repression. Nature 387: 16-17, 1997.

15. Ogryzko VV, Kotani T, Zhang X, et al: Histone-like TAFs within the PCAF histone acetylase complex. Cell 94: 35-44, 1998

16. Grant PA, Schieltz D, Pray-Grant MG, et al: A subset of TAF(II)s are integral components of the SAGA complex required for nucleosome acetylation and transcriptional stimulation. Cell 94: 45-53, 1998.

17. Hoshikawa Y, Kwon HJ, Yoshida M, Horinouchi S and Beppu T: Trichostatin A induces morphological changes and gelsolin expression by inhibiting histone deacetylase in human carcinoma cell lines. Exp Cell Res 214: 189-197, 1994.

18. Darkin-Rattray SJ, Gurnett AM, Myers RW, et al: Apicidin: a novel antiprotozoal agent that inhibits parasite histone deacetylase. Proc Natl Acad Sci USA 93: 13143-13147, 1996.

19. Kim MS, Son MW, Kim WB, Park YI and Moon A: Apicidin, an inhibitor of histone deacetylase, prevents H-ras-induced invasive phenotype. Cancer Lett 157: 23-30, 2000.

20. Kim JS, Lee S, Lee T, Lee YW and Trepel JB: Transcriptional activation of $\mathrm{p} 21^{\mathrm{WAF} 1 / \mathrm{CIP} 1}$ by apicidin, a novel histone deacetylase inhibitor. Biochem Biophys Res Commun 281: 866-871, 2001.

21. Takai N, Desmond JC, Kumagai T, et al: Histone deacetylase inhibitors have a profound anti-growth activity in endometrial cancer cells. Clin Cancer Res 10: 1141-1149, 2004. 
22. Takai N, Kawamata N, Gui D, Said JW, Miyakawa I and Koeffler HP: Human ovarian carcinoma cells: Histone deacetylase inhibitors exhibit antiproliferative activity and potently induce apoptosis. Cancer 101: 2760-2770, 2004.

23. Bannister AJ and Kouzarides T: The CBP co-activator is a histone acetyltransferase. Nature 382: 641-643, 1996.

24. Ogryzko VV, Schiltz RL, Russanova V, Howard BH and Nakatani Y: The transcriptional coactivators p300 and CBP are histone acetyltransferases. Cell 87: 953-959, 1996.

25. Mizzen CA, Yang XJ, Kokubo T, et al: The TAF(II)250 subunit of TFIID has histone acetyltransferase activity. Cell 87: 1261-1270, 1996.

26. Nagy L, Kao HY, Chakravarti D, et al: Nuclear receptor repression mediated by a complex containing SMRT, mSin3A, and histone deacetylase. Cell 89: 373-380, 1997.

27. Hassig CA, Fleischer TC, Billin AN, Schreiber SL and Ayer DE: Histone deacetylase activity is required for full transcriptional repression by mSin3A. Cell 89: 341-347, 1997.

28. Laherty CD, Yang WM, Sun JM, Davie JR, Seto E and Eisenman RN: Histone deacetylases associated with the $\mathrm{mSin} 3$ corepressor mediate mad transcriptional repression. Cell 89: 349-356, 1997.

29. Johnson DG and Walker CL: Cyclins and cell cycle checkpoints. Annu Rev Pharmacol Toxicol 39: 295-312, 1999.

30. Cairns P, Polascik TJ, Eby Y, et al: Frequency of homozygous deletion at p16/CDKN2 in primary human tumors. Nat Genet 11: 210-212, 1995 .

31. Nakagawa K, Conrad NK, Williams JP, Johnson BE and Kelly MJ: Mechanism of inactivation of CDKN2 and MTS2 in non-smallcell lung cancer and association with advanced stage. Oncogene 11: 1843-1851, 1995.

32. Kinoshita I, Dosaka-Akita H, Mishina T, et al: Altered p16 and retinoblastoma protein status in non-small-cell lung cancer: potential synergistic effect with altered p53 protein on proliferative activity. Cancer Res 56: 5557-5562, 1996.
33. Barbieri F, Cagnoli M, Ragni N, Pedulla F, Fogalia G and Alama A: Expression of cyclin D1 correlates with malignancy in human ovarian tumors. Br J Cancer 75: 1263-1268, 1997.

34. Wong YF, Chung TH, Cheung T, et al: Methylation of p16 ${ }^{\mathrm{iNK} 4 \mathrm{~A}}$ in primary gynecologic malignancy. Cancer Lett 136: 231-235, 1999.

35. Takeichi M: Cadherin cell adhesion receptors as a morphogenetic regulator. Science 251: 1451-1455, 1991.

36. Graff JR, Herman JG, Lapidus RL, et al: E-cadherin expression is silenced by DNA hypermethylation in human breast and prostate carcinomas. Cancer Res 55: 5195-5199, 1995.

37. Nass SJ, Hermann JG, Gabrielson E, Iversen PW, Davidson NE and Graff JR: Aberrant methylation of the estrogen receptor Ecadherin 5' CpG island increases with malignant progression in human breast cancer. Cancer Res 15: 4346-4348, 2000.

38. Saito T, Mishimura M, Yamasaki H and Kudo R: Hypermethylation in promoter region of E-cadherin gene is associated with tumor differentiation and myometrial invasion in endometrial carcinoma. Cancer 15: 1002-1009, 2003.

39. Cameron EE, Backman KE, Myohanen S, Herman JG and Baylin SB: Synergy of demethylation and histone deacetylase inhibition in the re-expression of genes silenced in cancer. Nat Genet 21: 103-107, 1999.

40. Sherr CJ: G1 phase progression: cyclin on cue. Cell 79: 551-555, 1994.

41. Kyushima N, Watanabe J, Hata H, Jobo T, Kameya T and Kuramoto H: Expression of cyclin A in endometrial adenocarcinoma and its correlation with proliferative activity and clinicopathological variables. J Cancer Res Clin Oncol 128: 307-312, 2002. 